\title{
Comparative study on wave hindcasting using wind downscaling data at Bojong Salawe Beach
}

\author{
Eka Oktariyanto Nugroho ${ }^{1, *}$, Benedictus Arie Moniaga ${ }^{2}$, Fitri Suciaty ${ }^{2}$, Asrini Chrysanti ${ }^{1}$, Dhemi Harlan ${ }^{1}$, and \\ Muhammad Syahrial Badri Kusuma ${ }^{1}$ \\ ${ }^{1}$ Water Resources Engineering Research Group, Faculty of Civil and Environmental Engineering, Institut Teknologi Bandung, \\ Bandung, Indonesia \\ ${ }^{2}$ Department of Civil Engineering, Faculty of Civil Engineering and Planning, National Institute of Technology, Bandung, Indonesia
}

\begin{abstract}
The wind data have a crucial role in shore construction engineering, but the availability data is commonly rare. Some research and recording station provide wind data with four times data record in a day. This research calculated the wave as resulted of the downscaled wind data from four times a day to twenty four times a day recording. The research done by comparing several data obtained from satellite record and land-station record. The results show similarity in wind velocity and dominance direction but have significant differences of wave height and the direction of wave from difference record locations.
\end{abstract}

\section{Introduction}

The existence of the wind data is very important in the civil engineering point a view in general and became a role key in the port design. In the design process, the wind data can describe the characteristic of the location. Time constraints and information in obtaining wind data become obstacles so that primary data surveys conducted in short time must be processed in such a way as to provide complete information of the wind characteristics of the location. This research is focusing in the comparison of wind data between the datasets recorded from the satellite and land-stations to determine the pattern of differentiation before and after downscaled.

\section{Theoretical background}

The research uses certain empirical literature study to calculate wave hindcasting and conduct the downscaling data. The theoretical calculations involved are wind, hindcast, empirical and linier approaches.

\subsection{Wind}

Wind is air in motion, produced by the uneven heating of the earth's surface by the sun. Since the earth's surface is made of various land and water formations, it absorbs the radiation of the sun unevenly and it created different temperatures and air pressure. The difference of temperature and air pressure determines the speed and the direction of the wind itself. There are two necessary correction factors to specify the wind data such as location and wind data correction itself.

\subsection{Wind correction factor}

Wind correction factor used to equate the difference location of recorded data. Wind data correction factor adapted from empirical study of JONSWAP as in Shore Protection Manual Volume 1 [1,2] and Baitjes et al [3]. The correction of wind data involves height, stability, and temperature as shown in Equation 1, Equation 2, Equation 3 and Fig. 1.

$$
\begin{aligned}
U(10) & =U(\mathrm{z})(10 / \mathrm{z})^{(1 / 7)} \\
U & =R \mathrm{~T} U(10) \\
U \mathrm{~A} & =0.71(\mathrm{U})^{(1.23)}
\end{aligned}
$$

\footnotetext{
With :

$U_{(10)}=$ Wind speed at 10 metres elevation $(\mathrm{m} / \mathrm{s})$,

$U_{(z)}=$ Wind speed at $\mathrm{z}$ metres elevation $(\mathrm{m} / \mathrm{s})$,

$Z \quad=$ Measurement's elevation $(m)$,

$U=$ Corrected wind speed $(\mathrm{m} / \mathrm{s})$,

$R_{T} \quad=$ Stability coefficient, Fig.1,

$U_{A}=$ Wind stress factor $(\mathrm{m} / \mathrm{s})$.
}

\footnotetext{
* Corresponding author: nugrohoeka@,ftsl.itb.ac.id
} 


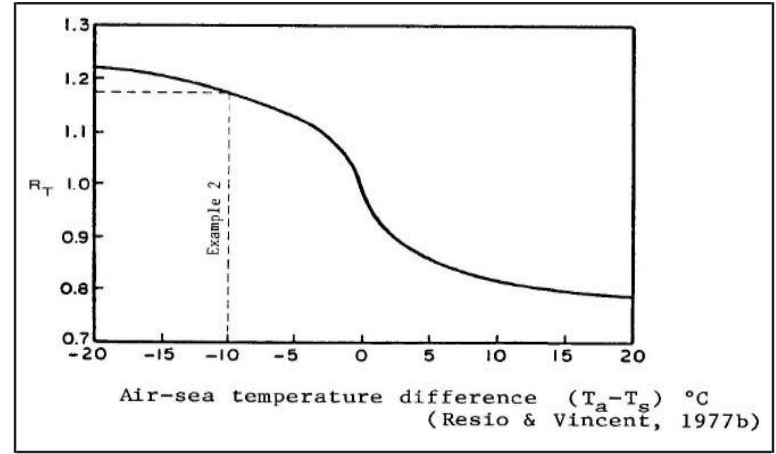

Fig. 1. Correction of stability graph from Resio and Vincent, 1977b [4] (Shore Protection Manual Volume 1, [1]).

\subsection{Correction of location}

Correction of location is used to correct the data recorded if the data is not from the sea such as land station. The correction of location graph is shown below.

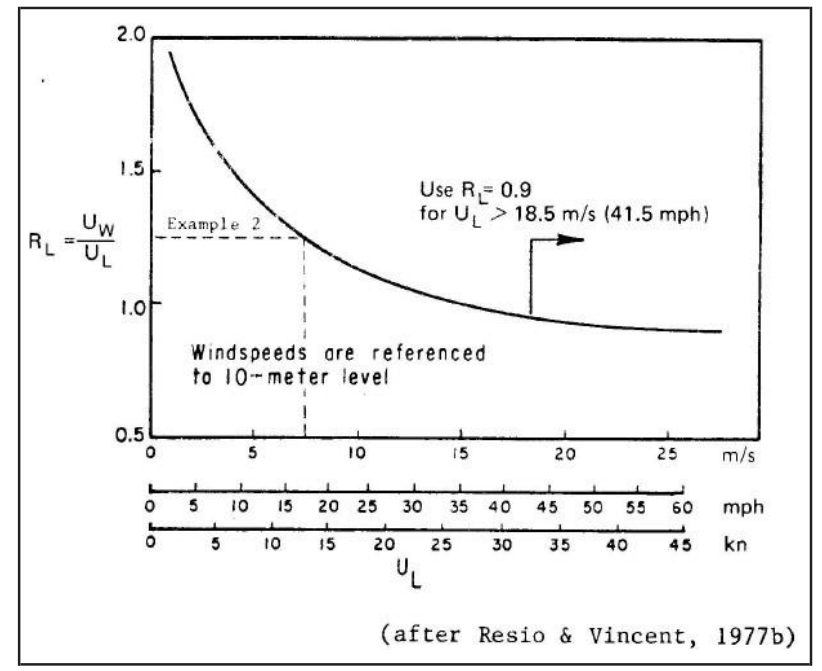

Fig. 2. Correction of location graph from Resio and Vincent, 1977b [4] (Shore Protection Manual Volume 1, [1]).

\subsection{Fetch}

Fetch is the distance travelled by wind or waves across open water with $200 \mathrm{~km}$ maximum length. Fetch is used to calculate the wave's period and height. Fetch effective is calculated by the following equation.

$$
F_{\text {eff }}=\left(\sum F_{i} \cos \alpha i\right) /\left(\sum \cos \alpha i\right)
$$

With :

$F_{i}=$ Fetch length $(\mathrm{km})$,

$\alpha i \quad=$ Frame angle $\left(^{\circ}\right)$.

\subsection{Hindcasting}

Hindcasting is a calculation process to generate wind data become a wave. Wave forming on the deep sea is analysed with empirical formulas as resulted from JONSWAP parametric model wave spectrum [1,2]. The equations shown in Figure 3.

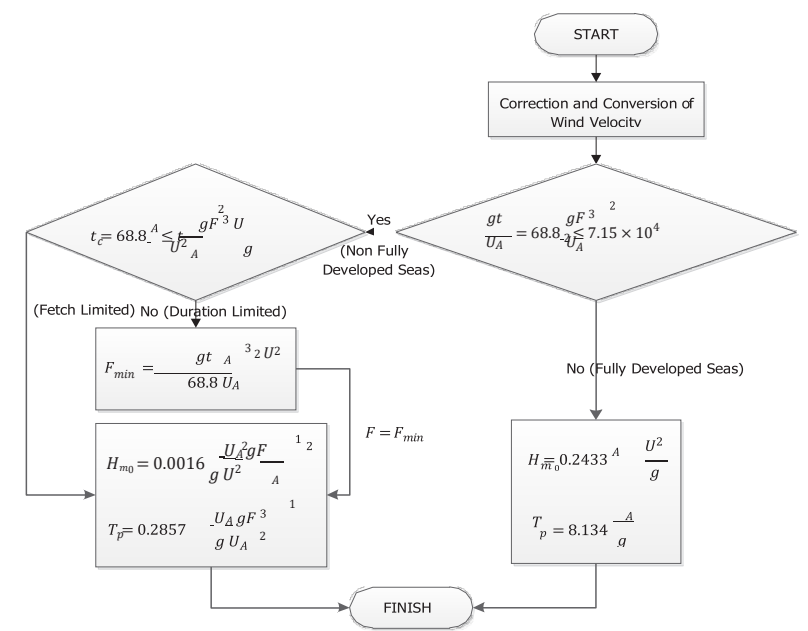

Fig. 3. Flow chart calculation for wave hindcasting $[1,2]$.

With :

$H m_{0}=$ the spectrally based significant wave height $(m)$,

$T P=$ the period of the peak of the wave $\operatorname{spectrum}(s)$,

$F \quad=$ the fetch $(m)$,

$T \quad=$ the duration $(s)$,

$T c=$ the duration using empirical formulae $(s)$,

$U_{A}=$ the wind stress factor $(\mathrm{m} / \mathrm{s})$,

$g \quad=$ the gravitation acceleration $\left(\mathrm{m} / \mathrm{s}^{2}\right)$.

\subsection{Downscaling}

Downscaling is a procedure to assume the high -resolution data based on variables on low resolution data. This technique commonly done by dynamics or statistical approach in several major such as meteorology, climatology, and long-distance forecast.

The first approach is using empirical equation to calculate wind speed. The equation adapted from Z. Guo [5] where the equation generated from validated data in a windy location to describe the characteristic of hourly wind speed.

With :

$$
W_{n}=W_{\text {ave }}+(1 / \pi) W_{\max } \cos [(n \pi) / 12]
$$

$W_{n} \quad=$ Hourly wind speed $(\mathrm{m} / \mathrm{s})$,

Wave = Daily average wind speed $(\mathrm{m} / \mathrm{s})$,

$W_{\max }=$ Daily maximum wind speed $(\mathrm{m} / \mathrm{s})$,

$n \quad=$ Wind occur time (hour).

The second approach is using linier equation where all the low resolutions data assumed as a linier data. This approach is used for downscaling the direction of wind data. Equation 6 is the equation that used for linier approaching.

$$
\left(y-y_{1}\right) /\left(y_{2}-y_{1}\right)=\left(x-x_{1}\right) /\left(x_{2}-x_{1}\right)
$$

\section{Research methodology}

In this research, there used five groups of data which are named after the location where the data were collected which are BMKG Cilacap and NOAA [6] Pangandaran. The data labelled with BMKG means that it retrieved from land station and NOAA means the data from satellite recording. The data are analysed with downscaling 
method, wind rose, wave rose, also maximum and significant wave height.

The location is at Bojong Salawe Beach, Pangandaran, West Java with $7^{\circ} 49^{\prime} 53.62^{\prime \prime S} 108^{\circ} 36^{\prime} 12.99^{\prime \prime E}$ as fetch coordinate as shown in Figure 4.

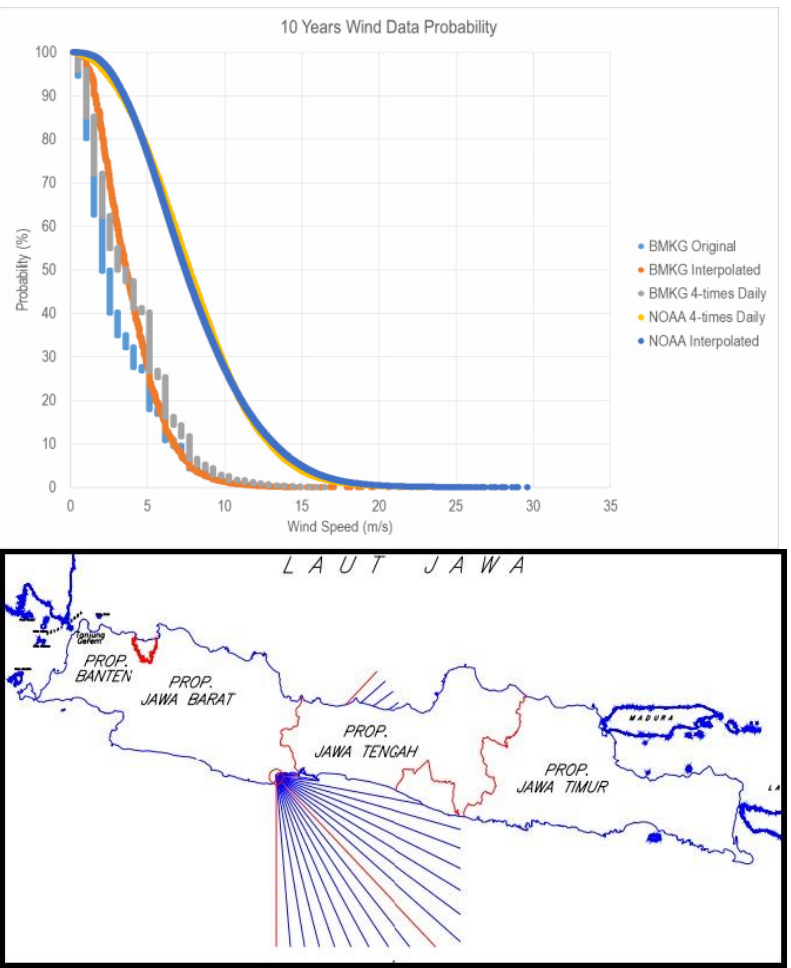

Fig. 4. Fetch point at Bojong Salawe beach, Pangandaran.

The procedure in this research is shown in Figure 5. The flowchart diagram determines the order of research procedure.

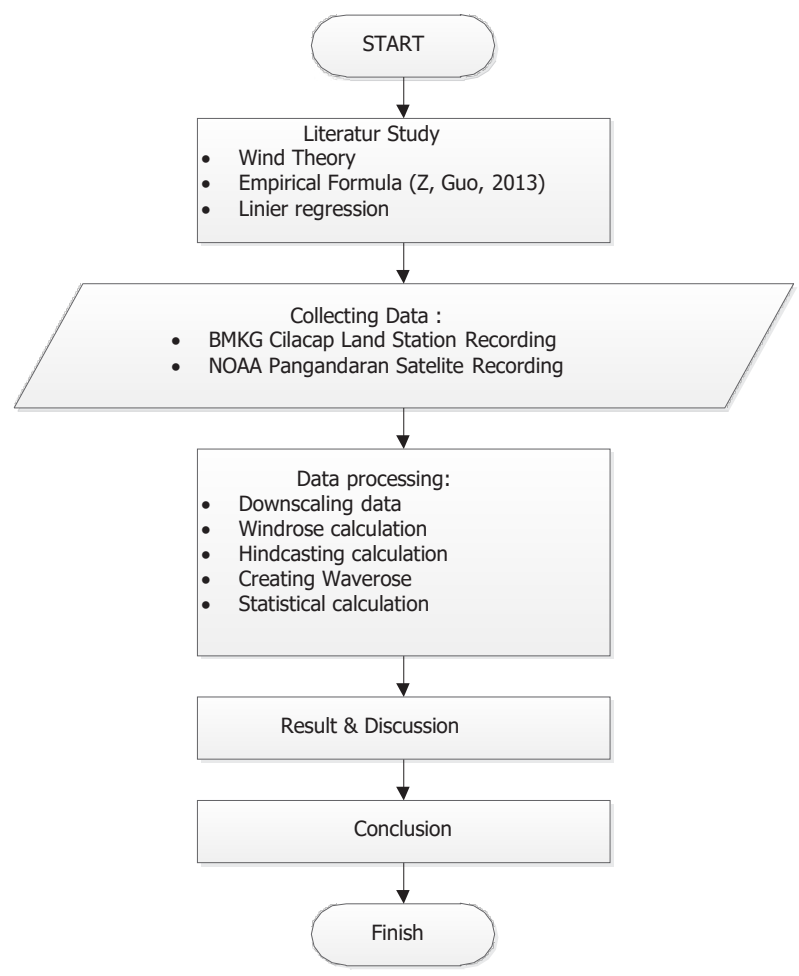

Fig. 5. Flowchart procedure of the research.

\section{Data analysis and result}

\subsection{Statistical analysis}

Data comparison is divided into 2 main groups which are BMKG and NOAA data. The analysis then can be extended to five groups of data which are: BMKG Original (24-times daily), BMKG 6 hours (4-times daily), $\mathrm{BMKG}$ interpolation (interpolated data from BMKG 6 hours), NOAA 6 hours (4-times daily) and NOAA interpolation (interpolated data from NOAA 6 hours). Wind data and wave data (generated from wind data) are analysed with Weibull probability analysis. The relation between those 2 groups of main data are shown on Figure 6 and Figure 7 with statistical characteristic compares as shown in Table 1.

Fig. 6. 10-years wind data probability chart.

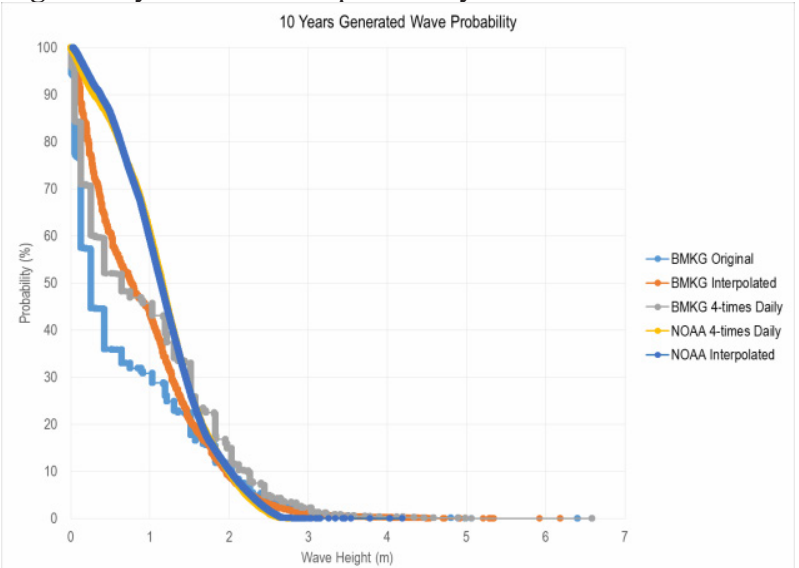

Fig. 7. 10-years wave generated data probability chart.

Figure 6 shows the probability pattern of 2 main groups of wind speed data BMKG and NOAA have a similarity before and after the data are being interpolated. A prove that the equation used for interpolation is valid to be used as a downscale equation for wind speed data.

The wind speed data of BMKG original data is coinciding with BMKG interpolated under $25 \%$ of probability wind speed with velocity over $5 \mathrm{~m} / \mathrm{s}$. It means that data with the velocity over $5 \mathrm{~m} / \mathrm{s}$ can be analysed with downscale method. In contrast, the BMKG 6 hours (4times daily) data almost coincide with BMKG interpolated in all probabilities of velocities of the wind speed.

The pattern between 4-times daily data and interpolated of BMKG also have the same pattern for the NOAA data. The NOAA 6 hours (4-times daily) data coincides with NOAA interpolated in all probabilities of velocities of the wind speed.

Figure 7 shows the chart shows that the probability of each group of waves generated data emerged is similar before and after the data is being interpolated. A prove that the equation used for interpolation is valid to be used as downscale equation for wind data and generated to wave height.

BMKG original is assumed as a benchmark data. The table shows that the significant generated wave height data are quite similar each other. The maximum generated wave height shows big differences with the 
benchmark data where the other data has lower maximum wave height compares to the benchmark data. The result of maximum wave shows the data from NOAA has similar value in $4 \mathrm{~m}$ wave height with earlier research by Salim, H [7].

Table 1. Statistical characteristic of generated waves.

\begin{tabular}{|c|c|c|c|c|c|}
\hline \multirow{2}{*}{ Statistical } & \multicolumn{6}{|c|}{ Generated Wave Height (m) } \\
\cline { 2 - 6 } & $\begin{array}{r}\text { BMKG } \\
\text { original }\end{array}$ & $\begin{array}{r}\text { BMKG } \\
\text { Interpolated }\end{array}$ & $\begin{array}{r}\text { BMKG } \\
6 \text { hour }\end{array}$ & $\begin{array}{r}\text { NOAA } \\
6 \text { hour }\end{array}$ & $\begin{array}{r}\text { NOAA } \\
\text { Interpolated }\end{array}$ \\
\hline Significant & 1,83 & 2,02 & 1,83 & 1,74 & 1,91 \\
\hline Maximum & 6,40 & 6,18 & 3,04 & 4,03 & 4,19 \\
\hline Minimum & 0 & 0 & 0 & 0 & 0 \\
\hline
\end{tabular}

\subsection{Wind Rose analysis}

The wind data (wind speed and wind direction) are plotted into a diagram called wind rose. The wind rose (Figure 8) then shows the difference between 2 main groups data (BMKG and NOAA) which have dominant direction and wind speed variety of each group of data. BMKG data is dominant direction in southwest and NOAA data is dominant direction in shouteast.

Figure 8 also shows that the dominant direction of each group of data before and after being interpolated is quite similiar and have a similiar direction frequency. It indicates that the interpolation of wind direction using linier approache is valid enough to be used as downscale equation for wind direction data.

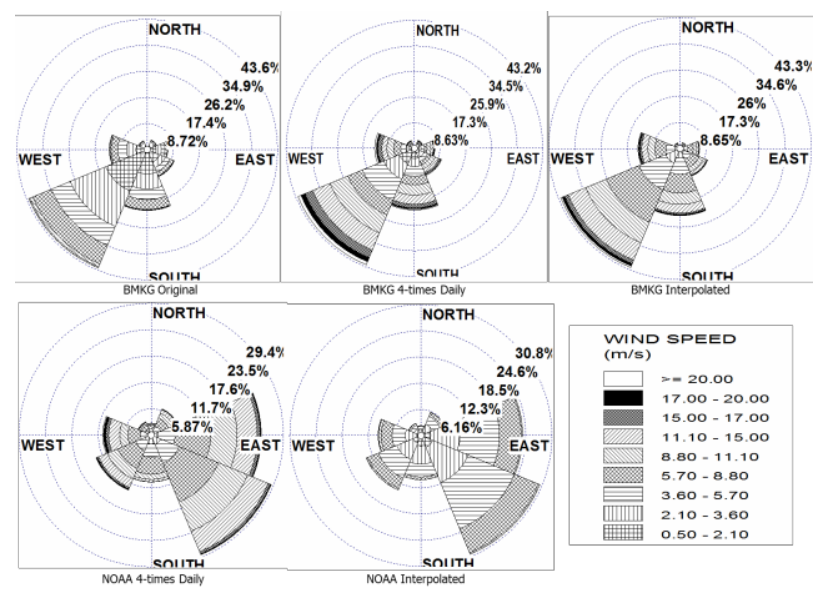

Fig. 8. 10-years wind rose.

\subsection{Wave Rose analysis}

The wind data of each group of data are generated to be wave data through hindcasting procedure. The data generated are plotted (in the same way as wind) to a diagram named wave rose. The wave rose (Figure 9) is a diagram which shows the difference of each group of waves data in wave height variety and dominant direction. Wave from BMKG data is dominant direction in south and wave from NOAA data is dominant direction in shouteast. Figure 9 shows that the dominant wave before and after interpolated of each group of data are coming from the same direction proving that the linier approach for wind direction is valid to be used as downscaling equation for wave as resulted of wind data generated.

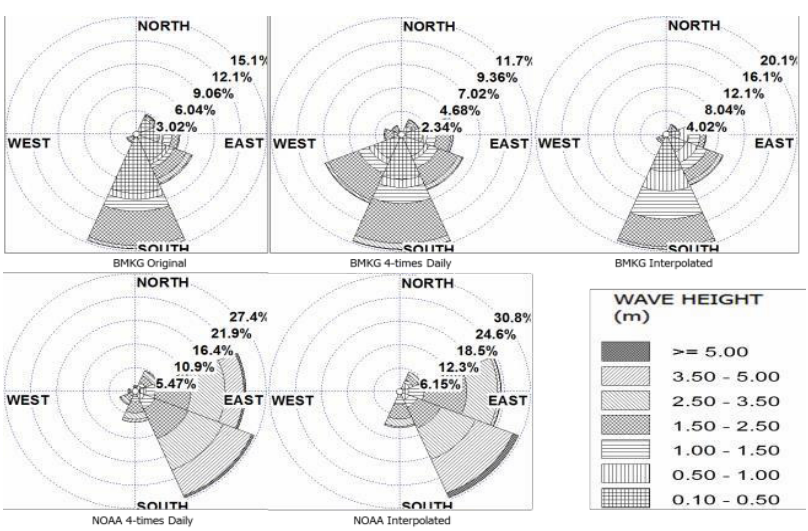

Fig. 9. 10-years wave rose.

\subsection{Maximum and significant wave analysis}

Wave hindcast shows that there are three dominant direction of wave coming: East, South East and South. Thus, the analysis of maximum and significant wave analysis will be taken from those three dominant directions.

Maximum and significant wave analysis shows the pattern of maximum and significant wave height occured every year of every group of data. The maximum data is the highest wave occured every year and the significant wave data is the $1 / 3$ of total ordered data.

Figure 10, Figure 11 and Figure 12 shows that the data groups named after BMKG have unpredictable maximum wave height value every year because the line have irregular line pattern. While the data groups named after NOAA have a regular pattern that may lead to projection of probable maximum annual wave height.

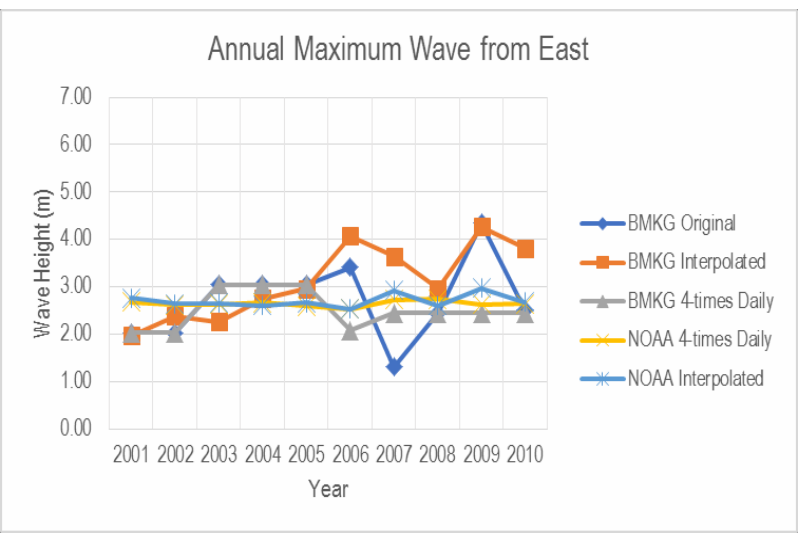

Fig. 10. Maximum wave pattern from east direction. 


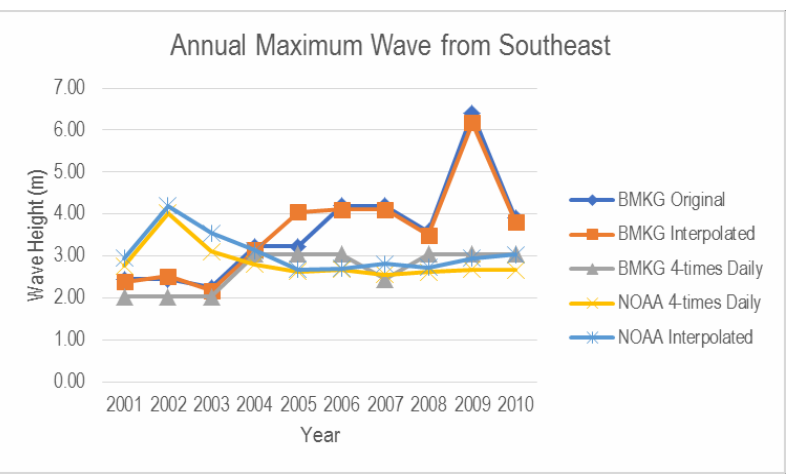

Fig. 11. Maximum wave pattern from southeast direction.

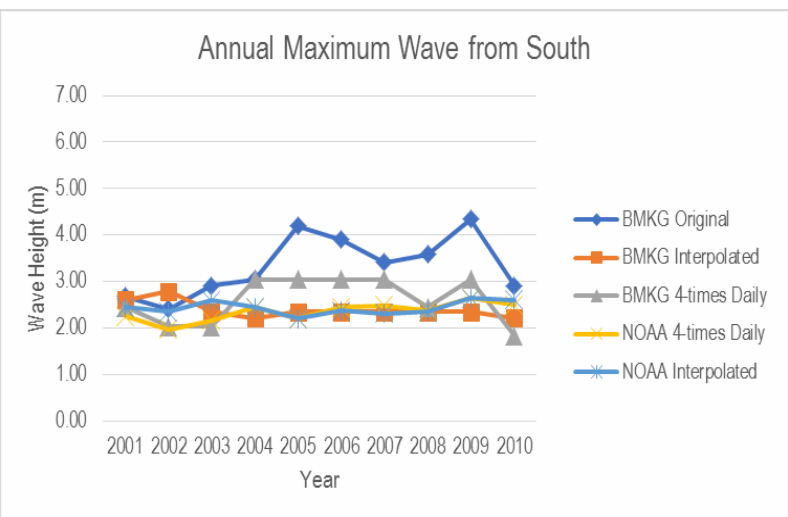

Fig. 12. Maximum wave pattern from south direction.

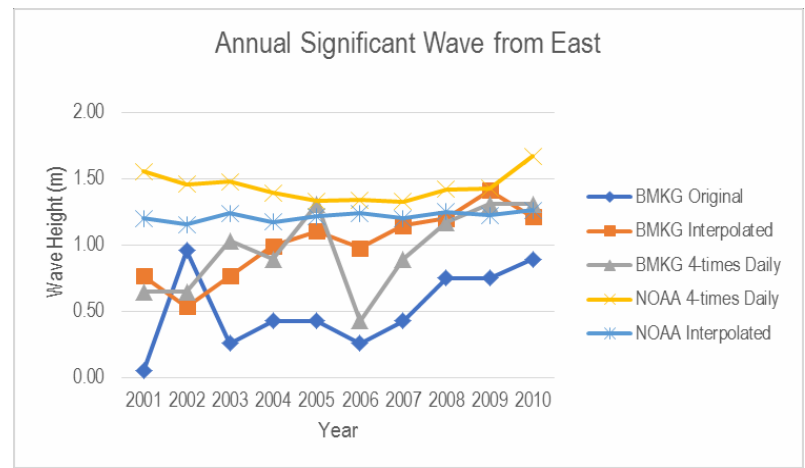

Fig. 13. Significant wave pattern from east direction.

Figure 10, Figure 11 and Figure 12 shows that the data groups named after BMKG have unpredictable maximum wave height value every year because the line have irregular line pattern. While the data groups named after NOAA have a regular pattern that may lead to projection of probable maximum annual wave height.

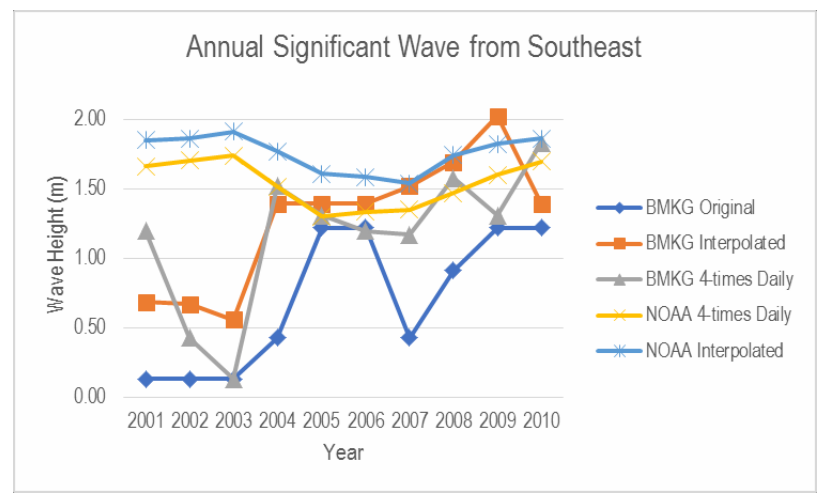

Fig. 14. Significant wave pattern from southeast direction.
Figure 13, Figure 14 and Figure 15 show that the data group named after BMKG are also unpredictable in significant parameter because it has irregular line pattern. While the NOAA data group have a regular pattern that may lead to a projection of probable significant annual wave height.

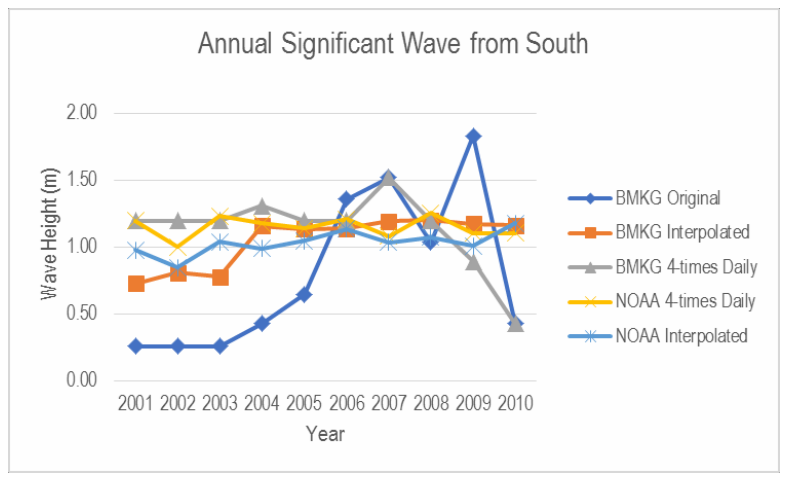

Fig. 15. Significant Wave Pattern Coming from South

\section{Conclusions and suggestion}

Based on the statistical, wind rose, wave rose and maximum and significant wave height analysis, the authors concludes that:

1. The gradient shown in Figure 6 and Figure 7 shows similarity of probability the emerged data before and after the downscaling process done. Thus, the downscaling toward the wind speed data using the empirical equation is considered valid,

2. Figure 8 and Figure 9 shows similarity of wind and wave dominant direction of each group of data before and after the downscaling process done. Thus, the downscaling toward the wind direction data using the linier approach equation is considered valid.

3. The gradient of probability is difference between the land station data and satellite data recording where the satellite data recording have relative bigger wind speed data value compared to land station data recording.

4. The BMKG original data acts as a benchmark data has a maximum wave height valued $6.40 \mathrm{~m}$.

5. There is a difference of annual maximum wave occurred in each data group where the land station data resulted $6.18 \mathrm{~m}$ and $3.04 \mathrm{~m}$ maximum wave height and the satellite data resulted $4.03 \mathrm{~m}$ and $4.19 \mathrm{~m}$. it may cause the planning of construction over design or under design.

6. Significant wave height before and after interpolated shows similarity between each group of data where the land station data resulted $1.83 \mathrm{~m}$ and $2.02 \mathrm{~m}$ and satellite data resulted $1.74 \mathrm{~m}$ and $1.91 \mathrm{~m}$.

7. Wave rose diagrams shows dominant direction diversion of every group of data compared where the land-station data shows south as dominant direction and satellite data shows south east as dominant direction.

8. All These results should be compared to the field wind measurement for the complete analysis in the next stage of the research. 
The authors would like to appreciate to ITB (Bandung Institute of Technology) for funding this research by Program Penelitian, Pengabdian kepada Masyarakat, dan Inovasi (P3MI) 2018.

\section{References}

1. U.S. Army Corps of Engineers, Shore Protection Manual (SPM) Volume 1, 4th ed., , US Army Engineer Waterways Experiment Station, Coastal Engineering Research Center, US Government Printing Office, Washington, DC, (1984)

2. K. Hasselmann, T. Barnett, E. Bouws, H. Carlson, D. Cartwright, K. Enke, J. Ewing, H. Gienapp, D. Hasselmann, P. Kruseman, Measurements of WindWave Growth and Swell Decay during the Joint North Sea Wave Project (JONSWAP); Deutches Hydrographisches Institut: Hamburg, Germany, 1973.

3. J. A. Baitjes, T. J. Zitman, and L. H. Holthuusen, $A$ reanalysis of the spectra observed in JONSWAP, J. Phys. Ocean., 17, pp. 1288-1295 (1987)

4. D. T. Resio, and C.L. Vincent, A numerical hindcast model for wave spectra on water bodies with regular shoreline geometry. Part II : Model verification with observed water data, Miscellaneous Paper H-77-9, Hydraulic Laboratory, U. S. Army Engineer Waterways Experiment Station, Vicksburg, Mississippi, (1977b)

5. Z. Guo, A simple method to downscale daily wind statistics to hourly wind data, arXiv preprint arXiv:1305.3367, Cornell university library, (2013)

6. Image provided by the NOAA/ESRL Physical Sciences Division, Boulder Colorado from their Web site at http://www.esrl.noaa.gov/psd/

7. H.T. Salim, M.S.B Kusuma, and Nazili, Mathematical Model of Split Growth in Serayu Estuary, Central java, Indonesia, The Sixteenth International Offshore and Polar Engineering Conference (ISOPE-2006), San Fransisco, California, USA 28 May - 2 June, (2006) 